\title{
Application research of power allocation based on Buck circuit in DC
}

\section{microgrid}

\author{
Zihao Wang, Mingyu Zhou \\ College of Electrical Engineering, Guangxi University, Nanning, China
}

\begin{abstract}
In a traditional DC microgrid, the power sharing control strategy has been always used in the distributed power converters, resulting in not making outer power allocation arbitrarily. In order to solve the power output allocation problem of wind power in DC microgrid, the intelligent Buck circuit based on PI algorithm and the load current feed-forward method was used to realize the arbitrary regulation of the output power of the wind power in the DC microgrid system. Compared with traditional distributed generators power-sharing method, the simulation and experimental results show the proposed method can realize arbitrary power outputting from distributed generators. Finally, the simulation and experimental results prove the validity and effectiveness of the control method.
\end{abstract}

\section{Introduction}

Due to the energy crisis in the new era and the pressure of environmental protection, the demand for new energy power generation technology is becoming increasingly urgent. The microgrid system consisting of new energy DG(distributed generations) has attracted much attention and support in society [1].Modern household appliances are mostly low voltage and small power DC loads. Thus, the small low-voltage DC microgrid receives more and more attention.

In traditional DC microgrid, the equal power sharing model with equal voltage and equal current is used. Literature [2] shows an average current model making the DC/DC converters outputting equal current; The active DC/DC module is studied in document[3]. However, these method can only achieve equal power outputting of each distribution power supply. These method cannot realize arbitrary power allocation from distributed power sources in DC microgrid system.

In this paper, we study two terminal low voltage DC microgrid based on wind power and batteries. The wind power simulator is connected with the new intelligent Buck in series and connected to the DC bus, and then connected to the resistive load. The structure of this paper is organized as follows: Section 2 presents structure and control method of two terminal
DC microgrid and new intelligent Buck circuit. Section 3 establishes the simulation and experimental results. Section 4 concludes the paper.

\section{The Structure and control strategy of dc microgrid}

\subsection{The Structure of Two-terminal DC Microgrid}

Nowadays, due to the use of a large number of low-voltage DC household appliances, low voltage DC micro grid has received more and more attention. Figue.1 shows a structure of a low-voltage two-terminal DC microgrid. The distributed generator DG connects to the DC bus trough a DC/DC converter. The wind power, always a AC power supply, rectifies into DC after trough rectifier and connects to DC bus trough the intelligent Buck circuit. Generally, DG is used as DC bus regulator, and a stable constant voltage source such as battery is always used to stabilize DC bus voltage. The system connects to a steady resistive load.

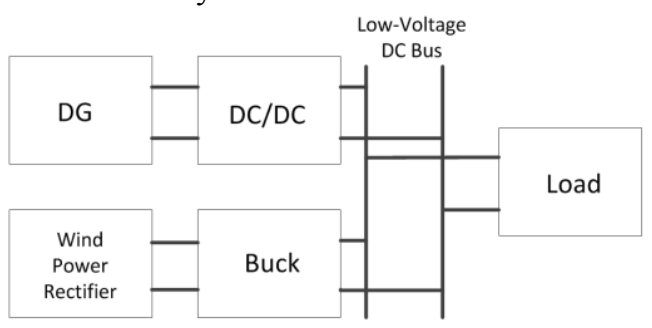

Figue.1. Structure of Two-terminal DC Microgrid 


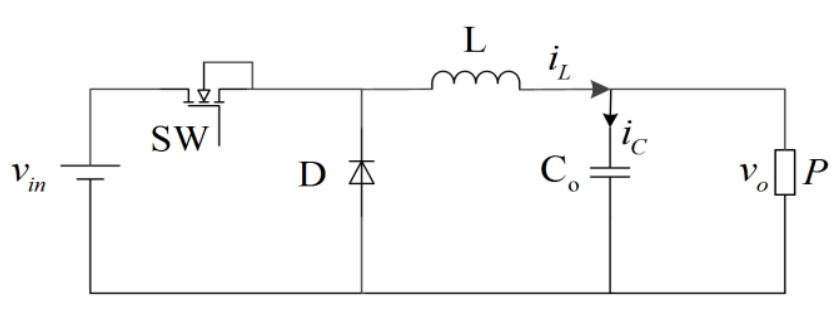

Figue. 2. Structure of new intelligent Buck converter

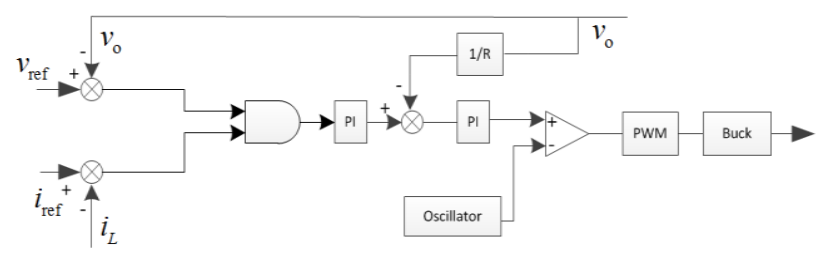

Figue. 3. Control structure of a new intelligent Buck circuit

\subsection{The Control of New intelligent Buck circuit}

The buck converter connecting the wind power rectifier in Figue. 2 is used to supply a constant power and current .The state - space equations of the buck converter when the switch is on (i.e., $0<t<d T$ ) and off (i.e., $d T<t<T$ ) are given by (1) and (2), respectively [3].

When $0<t<d T$ :

$$
\left\{\begin{array}{l}
\frac{d i_{L}}{d t}=\frac{1}{L}\left(v_{\text {in }}-v_{\mathrm{o}}\right) \\
\frac{d v_{o}}{d t}=\frac{1}{C}\left(i_{L}-\frac{P}{v_{o}}\right)
\end{array}\right.
$$

When $d T<t<T$ :

$$
\left\{\begin{array}{l}
\frac{d i_{L}}{d t}=\frac{1}{L}\left(-v_{o}\right) \\
\frac{d v_{o}}{d t}=\frac{1}{C}\left(\frac{P}{v_{o}}-i_{L}\right)
\end{array}\right.
$$

where $d$ and $T$ are the duty ratio and switching period of the converter, respectively. Using the state space averaging method the dynamic model of the buck converter can be written as

$$
\left\{\begin{array}{l}
\frac{d i_{L}}{d t}=\frac{1}{L}\left(v_{i n} d-v_{o}\right) \\
\frac{d v_{o}}{d t}=\frac{1}{C}\left(i_{L}-\frac{P}{v_{o}}\right)
\end{array}\right.
$$

Consider small perturbations in small-signal model[4]:

$$
\left\{\begin{array}{l}
v_{\text {in }}=V_{\text {in }}+\tilde{v}_{\text {in }} \\
d=D+\tilde{d} \\
v_{o}=V_{o}+\tilde{v}_{o} \\
i_{L}=I_{L}+\tilde{i}_{L}
\end{array}\right.
$$

Where $V_{\text {in }}, \mathrm{D}, V_{\mathrm{o}}$, and $I_{L}$ are the average values of $v_{\text {in }}, \mathrm{d}, v_{\mathrm{o}}$ and $i_{L}$, respectively. Substitute (4) into (3), the dynamic model of the buck converter becomes

$$
\left\{\begin{array}{l}
\frac{d \tilde{i}_{L}}{d t}=\frac{1}{L}\left(V_{i n} \tilde{d}+D \tilde{v}_{i n}-\tilde{v}_{\mathrm{o}}\right) \\
\frac{d \tilde{v}_{\mathrm{o}}}{d t}=\frac{1}{C}\left(\tilde{i}_{L}-\frac{P \tilde{v}_{o}}{V_{\mathrm{o}}^{2}}\right)
\end{array}\right.
$$

Note considering the fact that $V_{o} \square \tilde{v}_{o}$ :

$$
\left\{\begin{array}{l}
I_{L}-\frac{P}{v_{o}}=\frac{P}{V_{o}}-\frac{P}{V_{o}+\tilde{v}_{o}}=\frac{P \tilde{v}_{o}}{V_{o}\left(V_{o}+\tilde{v}_{o}\right)}=\frac{P \tilde{v}_{o}}{V_{o}^{2}} \\
I_{L}=\frac{P \tilde{v}_{o}}{V_{o}^{2}}+\frac{P}{v_{o}}
\end{array}\right.
$$

The transfer functions of the system can be obtained from (4) as follows:

$$
\left\{\begin{array}{l}
H_{1}(\mathrm{~s})=\frac{\tilde{v}_{o}(s)}{\tilde{d}(s)}=\frac{\frac{V_{\text {in }}}{L C}}{s^{2}-\left(\frac{P}{C V_{o}^{2}}\right) s+\frac{1}{L C}} \\
H_{2}(\mathrm{~s})=\frac{\frac{D}{L C}}{\tilde{v}_{\text {in }}(s)}=\frac{\frac{P}{P}}{s^{2}-\left(\frac{P}{C V_{o}^{2}}\right) s+\frac{1}{L C}}
\end{array}\right.
$$

Considering the steady constant load based on a linearized small-signal model, it can expand into a big-signal model[5]. The transfer function of the buck converter with a steady load can be obtained as:

$$
H_{3}(s)=\frac{\tilde{v}_{o}(s)}{\tilde{d}(s)}=\frac{\frac{V_{\text {in }}}{L C}}{s^{2}+\frac{1}{R C} s+\frac{1}{L C}}
$$

where the two poles are in the left half plane. Therefore, the system is stable.

The control structure of a new intelligent Buck circuit is shown in Figue.3.

The current source voltage and current control method is used in this paper. This method compares the 
load voltage $v_{\mathrm{o}}$ and the reference voltage $v_{\text {ref }}$ to prevent external voltage suddenly increasing that results in a sudden increase in load over voltage damaging and system collapsing. Linear PI controllers can be designed to stabilize the system around a specific operating point based on a linearized small-signal model. And the system is stable from (8).

\section{Simulation and experiment results}

\subsection{The Simulation results}

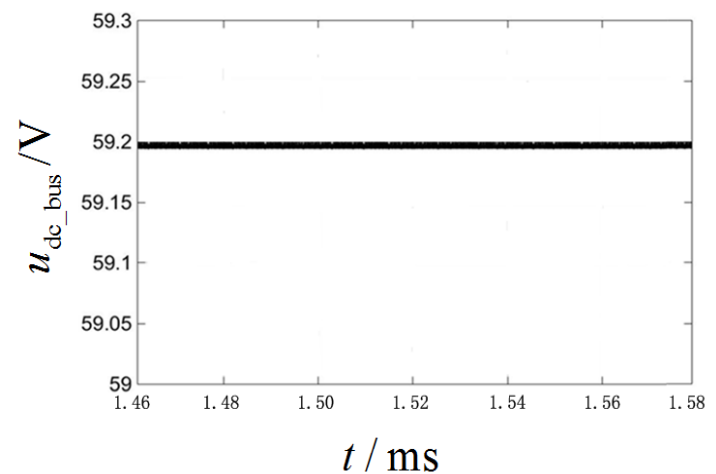

Figue.4. DC bus voltage when inductor outputting 4A

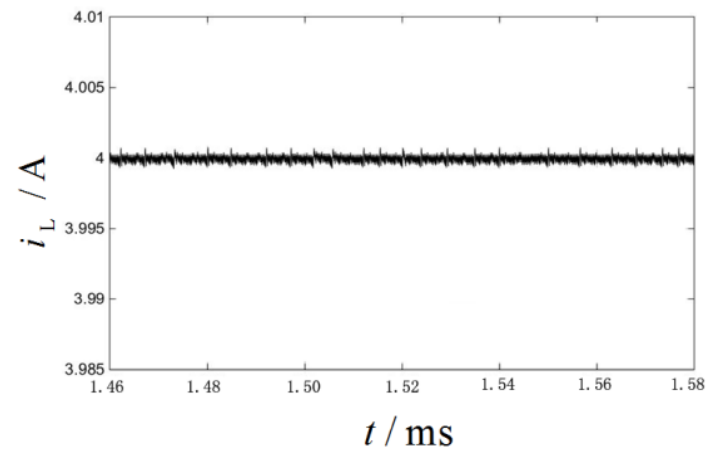

Figue.5. Inductor current when inductor outputting 4A

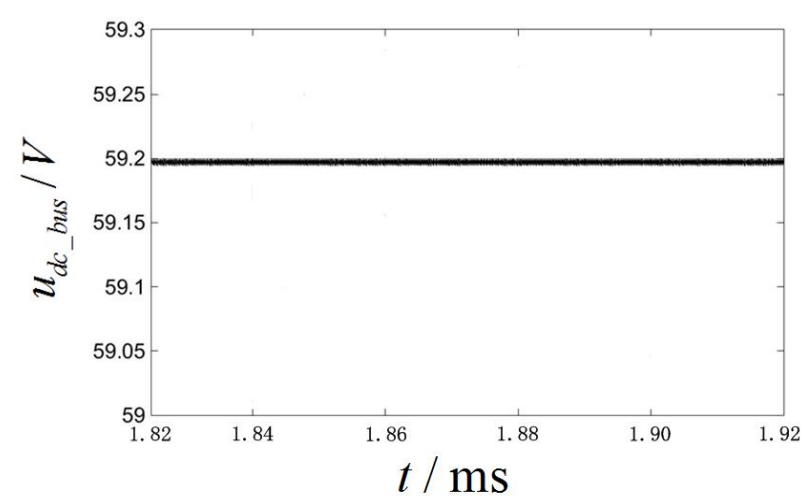

Figue.6. DC bus voltage when inductor outputting $6 \mathrm{~A}$

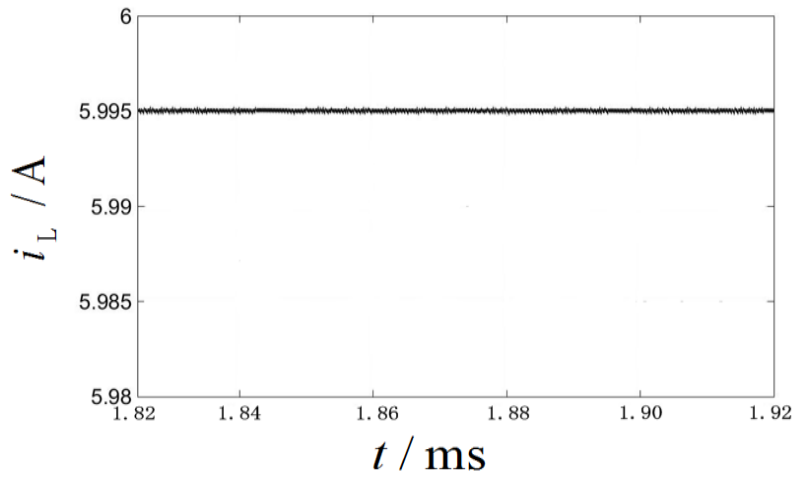

Figue.7. Inductor current when inductor outputting 6A

To verify validity and effectiveness of the control method in this study, a simulation model is built in MATLAB/Simulink using a two-terminal DC microgrid model. A $60 \mathrm{~V}$ battery is used as the DC microgrid bus voltage regulator. Wind power simulator fluctuates at $100 \mathrm{~V}-120 \mathrm{~V}$ according to the simulation curve and connects to the intelligent Buck circuit after rectified through a uncontrolled full bridge rectifier. As for the intelligent Buck circuit, the inductor is $0.1 \mathrm{mH}$,the switching frequency is $50 \mathrm{kHz}$, and the constant resistive load is $10 \Omega$.The simulations results are shown in Figue.4-Figue.7.As shown in Figue.4 and Figue.5,the DC bus voltage is $59.2 \mathrm{~V}$ and inductor outputs $4 \mathrm{~A}$ current. Then we can know that the wind power outputs 4A and battery outputs $6 \mathrm{~A}$ for the load. As shown in Figue. 6 and Figue.7,the DC bus voltage is $59.2 \mathrm{~V}$ and inductor outputs $6 \mathrm{~A}$ current . Then we can know that the wind power outputs $6 \mathrm{~A}$ and battery outputs $4 \mathrm{~A}$ to the load.

As shown in Figue.6 and Figue.7, the proposed algorithm can realize the free adjustment of the output power of the distributed power supply. In Figue.5, the inductance current is $4 \mathrm{~A}$. The Figue.4-Figue. 7 show that when the output current of wind power rectifier is changed, Figue. 4 and Figue. 6 show DC microgrid bus voltage is constant $59.2 \mathrm{~V}$, and the inductor current changed from $4 \mathrm{~A}$ of Figue.5 to $6 \mathrm{~A}$ of Figue.7.The simulations show that this algorithm can realize power outputting arbitrarily. 


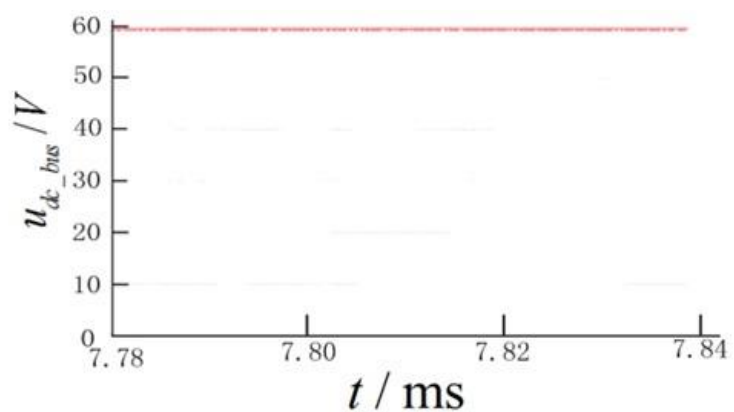

Fig.8. DC bus voltage 1

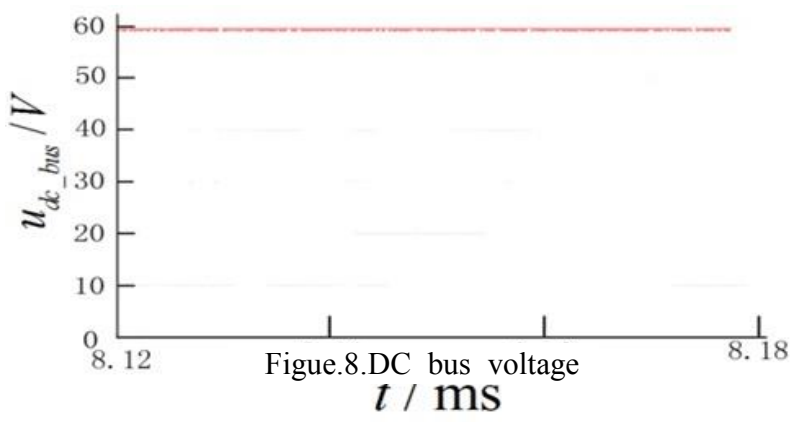

Fig. 10 DC bus voltage 2

\subsection{The Experiment results}

A $60 \mathrm{~V}$ battery is used as the DC microgrid bus voltage regulator. Wind power simulator fluctuates at $100 \mathrm{~V}-120 \mathrm{~V}$ according to the simulation curve and connects to the intelligent Buck circuit after rectified through a uncontrolled full bridge rectifier. The intelligent Buck circuit selects a $0.1 \mathrm{mH}$ inductor, $50 \mathrm{kHz}$ switching frequency and DSP28335 as a controller to realize the contru Figue.10.DC bus voltage is $100 \Omega$.A $0.1 \Omega$ copper wire is connected with the load of the Buck circuit, and the signal $u_{L r}$ is amplified by LM324 shown in Figue.9 and Figue.11 .

The DC bus is $59 \mathrm{~V}$ shown in 8 when two-terminal works. As shown in , $u_{L r}$ is $0.10 \mathrm{~V}$ so the output current of the inductor is $0.2 \mathrm{~A}$ by the corresponding amplification factor. We can know that battery output $0.4 \mathrm{~A}$ so the power allocation rate is about 1:2 The DC bus is $59 \mathrm{~V}$ shown in Figue.10 when two-terminal working. As shown in Figue.11, $u_{L r}$ is $0.2 \mathrm{~V}$ so the output current of the inductor is $0.4 \mathrm{~A}$ by the corresponding amplification factor. We can know that battery output $0.2 \mathrm{~A}$ so the power allocation rate is about $2: 1$.

As can be seen from Figue. 8 to Figue.11, the DC bus
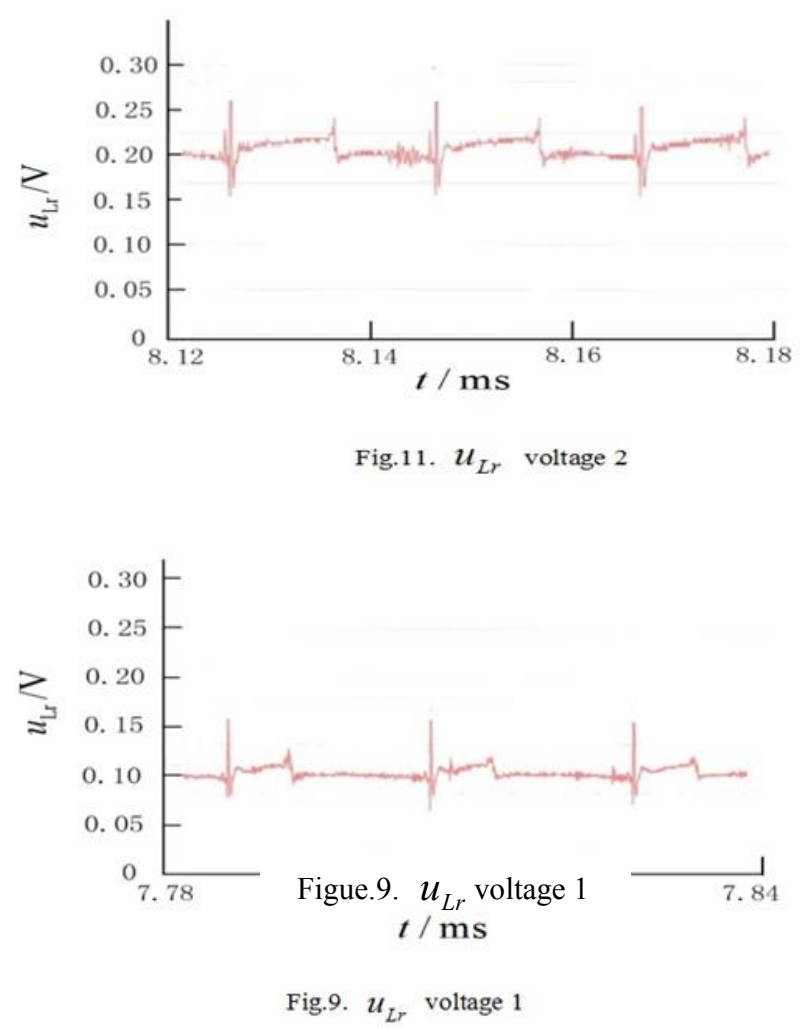

is constant $59 \mathrm{~V}$ based on the proposed algorithm when wind power output arbitrarily. The results are the same as the simulation shown in Figue. 4 to Fig7.

\section{Conclusions}

In this paper, we clarify the space-state of Buck circuit and propose a power allocation algorithm based on PI and load current feed-back. Then we built a two-terminal DC microgrid in MATLAB/Simulink and validate the effer Figue.11. $u_{L r}$ voltage 2 rithm in a real battery and wind power two-terminal $D C$ system. The simulation and experiment results prove the validity and effectiveness of the control method.

\section{REFERENCES}

[1] N. H. Doerry, "Next generation integrated power systems for the future fleet," in Proc. IEEE Elect. Ship Technol. Symp., Apr. 20-22, 2009, pp. 1-27.

[2] N.H.Doerry and J. Amy, "Functional decomposition of amediumvoltage DC integrated power system," in Proc. ASNE Symp. Shipbuilding Support Global War Terrorism, Apr. 14-17, 2008, pp. 1-21.

[3] A. Griffo, J. Wang, and D. Howe, "Large signal stability analysis of DC power systems with constant power loads," in Proc. IEEE Veh. Power Propulsion Conf., Sep. 3-5, 2008, pp. 1-6.

[4] R.D. Middlebrook and S. Cuk, "A general unified approach to modeling switching converter power stages," in Proc. IEEE Power Electron. Spec.Conf., Jun. 8-10, 1976, pp. 18-34.

[5] C.N. Onwuchekwa and A. Kwasinski, "Analysis of boundary control for buck converters with instantaneous constant-power loads," IEEE 
Transactions on Power Electronics, vol. 25, no. 8, pp. 2018-2032, Aug 2010. 